\title{
NILAI AGAMA DALAM WAWACAN HIKAYAT HASAN SHOIG BASHRI UNTUK BAHAN AJAR MEMBACA DI SMA KELAS XII
}

\author{
Rindi Vaivti Melandi, Dedi Koswara, Usep Kuswari \\ Jurusan Pendidikan Bahasa Daerah FPBS UPI \\ Pos-el: Oriental_ndie@yahoo.com, dedi.koswara@upi.edu, usep.kuswari@upi.edu
}

\begin{abstract}
Abstrak
Penelitian ini bertujuan untuk memahami isi teks dan mendeskripsikan nilai-nilai agama dalam wawacan untuk dijadikan bahan ajar membaca di SMA kelas XII. Untuk mencapai hal itu, digunakan metode deskriptif dan metode edisi teks standar yang diharapkan bisa mendapatkan gambaran secara obyektif. Hasil penelitian ini menyimpulkan bahwa wawacan Hikayat Hasan Shoig Bashri merupakan sebuah naskah yang ditulis menggunakan huruf Arab Pegon dan ditransliterasi ke dalam huruf Latin. Wawacan ini dibagi ke dalam dua jilid, terdiri atas 128 halaman dan delapan pupuh yang bercerita mengenai kehidupan sosial seorang pemuda yang sangat taat pada ajaran agama yang dianutnya. Alur dari cerita wawacan ini adalah maju dan tokoh utamanya adalah Hasan Shoig Bashri. Secara umum, latar tempat yang digunakan adalah tempat-tempat yang erat hubungannya dengan agama Islam. Dalam penulisannya, pengarang menggunakan sudut pandang orang ketiga karena pengarang berada di luar cerita, selain itu pengarang juga menggunakan beberapa gaya bahasa, peribahasa Sunda, dan syair-syair Arab. Nilai agama yang terkandung dalam wawacan ini terdiri atas aqidah, akhlak, dan fiqih. Hasil temuan ini direkomendasikan untuk dijadikan bahan ajar sesuai SKKD mata pelajaran bahasa dan sastra Sunda.
\end{abstract}

Kata Kunci: wawacan, struktur intrinsik, nilai agama, dan bahan ajar

\section{RELIGIOUS VALUES IN HIKAYAT HASAN SHOIG BASHRI AS A READING MATERIAL IN GRADE XII OF SENIOR HIGH SCHOOL}

\begin{abstract}
This study aims to comprehend contents of the text and unearth the religious values in the text used as reading material in Grade XII of Senior High School. To meet the goal, this study used a descriptive method and a standard text method in hope to get an objective view. This study concludes that Hikayat Hasan Shoig Bashri is a text that was written through Arab Pegon and was transliterated into Latin alphabets. The text consists of two chapters, 128 pages and 8 pupuh. It tells a story of a moslem young man who obeyed his religion rules. Plot of the text is forward and the main actor is Hasan Shoig Bashri. Generally, the settings of the text are some places related with Islamic religion. The author of the text uses a third person viewpoint and uses a number of figurative speeches, Sundanese idioms, and even Arabic poetries. The religious values embedded in the text constitute Akidah, Akhlaq, and Fikih. The text is recommended to be a learning material suited with the standard competencies and basic competencies of Sundanese language and literature.
\end{abstract}

Keywords: text, religious values, and learning materials

\section{PENDAHULUAN}

Negara Indonesia kaya akan bermacammacam kebudayaan, baik dalam hasil kerajinan maupun dalam keseniannya. Kebudayaan adalah pikiran, karya, dan hasil karya manusia (Koentjaraningrat, 1985:1). Karya sastra merupakan bagian dari kebudayaan, karena karya sastra merupakan ekspresi pikiran dalam bentuk bahasa. 
Kehidupan sastra Sunda pertama kali ada dalam bentuk lisan. Karena mengalami perkembangan dari sastra lisan kepada sastra tulis, banyak karya sastra yang ditulis dalam bentuk naskah. Huruf yang digunakan dalam naskah adalah Cacarakan, Arab Pegon, Latin, Aksara Sunda Buhun, dan Jawa Kuna.

Berdasarkan isinya, naskah diklasifikasikan dalam beberapa kelompok, yaitu keagamaan, bahasa, hukum/adat istiadat, kemasyarakatan, mitologi/ legenda, pendidikan, pengetahuan, paririmbon, sastra, sastra sejarah, dan seni (Ekadjati, 1988). Terkadang isi naskah tidak serupa misalnya saja naskah sejarah, tidak semuanya sejarah, tapi dicampur dengan sastra. Salah satu naskah yang semua isinya sastra adalah wawacan (Ruhaliah, 2007: 14).

Naskah-naskah buhun bisa memberikan sumbangan pada studi mengenai satu bangsa atau satu kelompok sosial budaya yang melahirkan naskah-naskah tersebut, karena pada dasarnya naskah-naskah tersebut merupakan dokumen mengenai pikiran, rasa, dan pengetahuan dari bangsa atau kelompok sosial budaya tersebut (Ekadjati, 1988: 1) Pada kenyataannya karya sastra tradisional terutama naskah banyak yang tidak dipedulikan, karena sudah tersisihkan oleh karya sastra modern yang lebih gampang dibaca dan dimengerti. Salah satu hal yang mengakibatkan kurangnya kepedulian masyarakat pada naskah pada jaman sekarang adalah karena tulisan dan bahasanya yang tidak dimengerti.

Dalam penelitian ini, dibahas mengenai analisis naskah wawacan dilihat dari nilai agamanya. Naskah wawacan yang digunakan adalah wawacan yang berjudul Hikayat Hasan Shoig Bashri. Di dalamnya banyak menggambarkan kehidupan keagamaan pada jamannya. Agama yang terdapat pada wawacan ini adalah agama Islam.

Sastra Sunda menjadi salah satu bahan ajar di sekolah (SD, SMP, SMA), yang pengajarannya diatur dalam kurikulum yang ditetapkan oleh pemerintah dalam GBPP pengajaran sastra Sunda di sekolah. Berdasarkan SKKD, membaca wawacan menjadi salah satu Kompetensi Dasar yang harus diajarkan di SMA kelas XII.

Penelitian ini dilakukan, selain untuk menemukan nilai agama juga karena belum ada yang melakukan penelitian ini sebelumnya.

Tujuan dalam penelitian ini adalah untuk mengungkap nilai-nilai agama yang terdapat dalam wawacan Hikayat Hasan Shoig Bashri.

\section{METODE}

Metode yang digunakan dalam penelitian ini adalah metode deskriptif. Metode ini digunakan, karena diharapkan bisa mendeskripsikan analisis struktur dan nilai agama yang meliputi aqidah, akhlak, dan fiqih dalam wawacan Hikayat Hasan Shoig Bashri. Selain itu, dalam penelitian ini juga digunakan metode edisi standar untuk menggarap naskah yang ditulis dalam huruf Arab Pegon. Metode edisi standar adalah transliterasi naskah dengan cara memperbaiki kesalahan-kesalahan kecil dan yang tidak rata, ejahannya juga disesuaikan dengan ketentuan yang baru.

Sumber data dalam penelitian ini adalah wawacan Hikayat Hasan Shoig bashri dan sumber tertulis lainnya. Wawacan Hikayat Hasan Shoig Bashri berasal dari ibu Hj. Nénéng Nani Sumarni yang bertempat tinggal di Jl. Cigadung Raya Timur No.63 RT 05/02 Kelurahan Cigadung, Kecamatan Cibeunying Kalér. Naskah ini merupakan warisan turuntemurun yang pada jaman dahulu dipakai untuk acara marhabaan setelah melahirkan, ketika maulid nabi, dan dongeng untuk anak-anak yang mengaji. Sedangkan pada jaman sekarang naskah ini hanya dijadikan dokumen dan arsip.

Dalam penelitian ini, instrumen yang digunakan adalah kartu data yang berfungsi untuk menyimpan data-data yang dianalisis. Karya sastra dalam wawacan Hikayat Hasan Shoigh Bashri. Tujuannya adalah agar memudahkan dalam menganalisis data 
serta mudah dalam membuat kesimpulannya.

Wawacan adalah karya sastra naratif yang dibentuk dalam puisi pupuh, dalam pembacaannya biasanya suka dilagukan. Pupuh yang digunakan dalam wawacan, tidak hanya satu melainkan banyak dan berganti-ganti.

Menurut para ahli, wawacan dalam sastra Sunda bukan merupakan asli dari kesusastraan Sunda, tetapi merupakan pengaruh dari sastra Jawa. Masuknya ke sastra Sunda kira-kira pada abad ke-19.

Menurut Rosidi (1966: 12) dan Mukherjee (2001: 11) (dalam Ruhaliah, 2011: 9) wawacan bukan kesusastraan asli Sunda, tetapi pengaruh kesusastraan Jawa yang masuk ke wilayah Sunda terutama melewati kaum bangsawan (lingkungan kabupaten) dan kaum ulama (lingkungan pesantren). Oleh karena itu, wawacan bisa hidup dan dikenal oleh masyarakat di lingkungan tersebut.

Perkembangan wawacan di Sunda melewati beberapa tahap. Dalam tahap pertama, kehidupan wawacan dari sastra Jawa langsung disalin tidak disundakan, merupakan naskah. Tahap kedua, terlihat usaha menerjemahkan ke dalam basa Sunda, agar isinya bisa dimengerti oleh semua orang. Tahap ketiga bukan menerjemahkan, melainkan menciptakan cerita-cerita yang sudah ada dari dahulu dalam bentuk wawacan, seperti dongeng, hikayat, dan babad. Tahap keempat, setelah adanya teknologi cetak, wawacan yang tadinya merupakan naskah, banyak diterbitkan menjadi buku; diiringi oleh ciptaan-ciptaan baru dengan warna yang baru pula.

Istilah struktur sering ditemukan dalam ilmu bahasa dan sastra. Dalam bidang bahasa, yang disebut struktur adalah urutan komponen-komponen (unsur-unsur bahasa) sampai menjadi kata, frasa, klausa, atau kalimat. Sedangkan dalam sastra, adalah corak rakitan unsur-unsur sastra sampai menghasilkan karya sastra yang sempurna (Tamsyah, dkk., 1999:237).
Iskandarwassid (2003:153) menyebutkan bahwa yang disebut struktur dalam sastra Sunda adalah corak rakitan (susunan) komponen-komponen karangan sampai menghasilkan wujud karya sastra; sempurna mempunyai makna. Dalam prosa, contohnya bagaimana menggambarkan unsur-unsur tema, plot, dan tokoh, sampai bisa terbentuk menjadi cerita pendek atau novel.

Berdasarkan dua pendapat di atas, bisa disimpulkan bahwa struktur merupakan corak rakitan unsur-unsur sastra yang mempunyai makna untuk membentuk karya sastra seperti cerita pendek dan novel. Unsur-unsur karya sastra oleh Stanton (2012: 20) dikelompokkan menjadi tiga, di antaranya fakta-fakta cerita, tema, dan sarana-sarana cerita.

Nilai yang ada dalam karya sastra adalah nilai:

1) hedonik, adalah nilai yang bisa memberikan kabahagiaan secara langsung kepada pembacanya;

2) artistik, adalah nilai yang bisa memanifestasikan satu seni atau keterampilan dalam melakukan satu pekerjaan;

3) kultural, adalah nilai yang bisa memberikan atau mempunyai hubungan yang dalam dengan satu masyarakat, peradaban, atau kebudayaan;

4) etika, moral, agama, adalah nilai yang bisa memberikan petunjuk atau nasehat yang berkaitan dengan etika, moral, atau agama;

5) praktis, adalah nilai yang mengandung hal-hal praktis yang bisa diterapkan dalam kehidupan sehari-hari (Tarigan, 1984:195 dalam annadewigalery. blogspot.com )

Dalam sebuah karya sastra bisa terdapat lebih dari satu nilai. Dalam penelitian ini, yang dianalisis adalah nilai agamanya.

Secara umum, yang menjadi dasar dalam agama Islam adalah aqidah, akhlak, dan fiqih. Aqidah secara etimologis berarti 
'ikatan' dan angkutan, secara teknis berarti 'kepercayaan', 'keyakinan', 'iman', jadi aqidah adalah keyakinan hidup, iman dalam arti khusus yaitu pengikraran dalam hati (Anshari, 2004:44).

Akhlak adalah tabiat, watak, budi pekerti yang terpuji atau tercela yang tumbuh dalam jiwa manusia yang bisa melahirkan satu prilaku yang berkaitan dengan kejadian, yang menciptakan, dan yang diciptakan.

Fiqih adalah pemahaman para ulama terhadap syariat Islam yang ada dalam sumber hukum (Al-qur'an dan As-sunnah) serta dibuat secara sistematis dan praktis agar lebih mudah dimengerti. Karena fiqih merupakan hasil pemahaman manusia, jadi bentuknya tidak tetap, berkembang sesuai dengan perkembangan pemikiran dan perubahan budaya manusia dari jaman ke jaman. Bahan ajar merupakan segala bentuk bahan untuk syarat proses belajar dan mengajar agar bisa membantu guru/dosen/ instruktur serta murid dalam melaksanakan kegiatan pembelajaran.

Dilihat dari bentuknya, karya sastra yang harus diajarkan meliputi tiga macam, yaitu puisi, prosa, dan cerita drama (Koswara, 2009: 107). Berdasarkan jenisnya, karya sastra Sunda yang harus diajarkan meliputi:

1) Karya sastra Sunda buhun:

Jangjawokan, kakawihan, pupujian, sisindiran, pupuh, guguritan, wawacan, carita pantun, carita wayang, dongeng (hewan, legenda, babad, Si Kabayan, paranabi/wali, pamuk).

2) Karya Sastra Sunda Modérn:

Cerita pendek, sajak, novel, cerita drama.

\section{HASIL DAN PEMBAHASAN}

Berdasarkan hasil analisis data dalam wawacan Hikayat Hasan Shoig Bashri, ditemukan bahwa wawacan ini merupakan naskah yang ditulis menggunakan huruf Arab Pegon menggunakan bahasa Sunda. Wawacan ini dikarang oleh Haji Muhyidin, isinya dibagi ke dalam 2 jilid, yang masingmasing jilid tersebut terdapat 64 halaman.
Jilid pertama terdapat 723 bait pupuh, sedangkan jilid kedua terdapat 668 bait pupuh.

\section{Struktur Cerita Wawacan}

Struktur intrinsik yang dianalisis dalam penelitian ini adalah tema, alur, pelaku, latar, sudut pandang, dan gaya bahasa.

\section{1) Tema}

Tema dalam wawacan Hikayat Hasan Shoigh Bashri adalah kehidupan sosial seorang pemuda yang sangat taat pada agama yang dianutnya. Alur yang digunakan adalah alur maju karena dalam wawacan ini diperkenalkan terlebih dahulu tokoh utamanya lalu diceritakan kehidupannya dari awal hingga akhir cerita.

\section{2) Fakta-Fakta Cerita}

Dalam wawacan ini tercatat 33 orang pelaku, yang tokoh utamanya bernama Hasan Shoig Bashri. Pelaku kedua dalam wawacan ini tercatat 10 orang, di antaranya ibunya Hasan, Putri bungsu dan enam kakaknya, Gan Ayu Manarusana, Syeh Abdul Kudus, Syeh Abu Raisyi, Raja Malik Hasun, Syawahi Masyhur, dan Nurul Huda. Sedangkan pelaku tambahannya ada 22 orang pelaku, di antaranya adalah Khodamkhodam Bahram, lima putri adik Nurul Huda, Nashir dan Mansur, para istri di Hamam, Eneng Tuhpatulawadah, Masrur, empat pendeta di gua, jin iprit Dahnasy, pelayan raja Ardhul Kudus, Rais, askaraskar Jazair Waq, para putri kerajaan Nurul Huda, khodam-khodam nenek Syawahi, seribu prajurit Nurul Huda, raja Malikul Akbar, tukang ta'bir, seribu prajurit raja Malikul Akbar, 'abid-'abid, a'wan-a'wan, dua anaknya tukang sihir, tujuh ratu jin, dan jin iprit ketua seluruh jin di gunung.

Latar tempat dan waktu dalam wawacan ini sangat banyak tergambarkan karena seringnya tokoh utama dalam melakukan perjalanan. Selain itu, secara umum latar yang digunakan adalah latar yang erat hubungannya dengan agama Islam, misalnya saja latar tempat yang 
menceritakan keberadaan di Basrah dan Bagdad, sedangkan untuk latar waktu digunakan waktu dalam solat fardhu.

\section{3) Sarana-Sarana Cerita}

Sudut pandang dalam wawacan ini menggunakan sudut pandang orang pertama dan orang ketiga.

Gaya bahasa yang digunakan dalam wawacan ini adalah bahasa yang teratur sesuai patokan dalam aturan puisi pupuh. Hal itu yang membedakan antara wawacan dengan cerita prosa. Dalam wawacan ini banyak juga digunakan kata-kata yang berkaitan dengan keagamaan (agama Islam), yaitu syair-syair Arab. Selain itu, peribahasa Sunda, gaya bahasa personifikasi, perbandingan, hiperbola, dan purwakanti juga ditemukan dalam wawacan ini.

\section{Nilai Agama}

Nilai agama yang dianalisis dalam wawacan ini meliputi aqidah, akhlak, dan fiqih.

\section{1) Aqidah}

Aqidah yang terdapat dalam wawacan ini di antaranya adalah iman kepada Alloh, iman kepada qada' dan qadar (takdir), orang kafir akan rugi, dan adanya jin-jin yang diciptakan sama dengan manusia, yaitu tiada lain untuk beribadah kepada Alloh.

\section{Tangtu urang tinulungan, \\ ku pangéran Allah anu maha suci, kana ngalahkeun kamusuh, \\ Hasan jeung saputra garwa, sareng nini tiluhur kuda geus lungsur, naék kana luhur jabal, \\ kudana mah sina nyingkir.}

Iman artinya percaya. Iman kepada Alloh berarti percaya sepenuh hati adanya Alloh dan seluruh alam di dunia dan isinya merupakan ciptaanNya. Selain itu juga, percaya bahwa Alloh akan selalu melihat dan mengawasi di manapun dan kapanpun.
Dilihat dari bait pupuh di atas, terbukti bahwa Hasan mempunyai keimanan yang tinggi pada Alloh.

\section{Pinasti panggih nu pasti, nya wafat mulang ka Rohmat, énggalna nu dicarios, mayitna dipulasara, barangna dibagi dua, hiji-hiji putra tangtu, nyandak sabagéan séwang.}

Qada' artinya ketentuan Alloh swt sejak jaman Azali mengenai segala hal yang berkaitan dengan makhlukNya meliputi baik dan buruknya, hidup dan matinya. Sedangkan qadar adalah wujud dari ketentuan Alloh terhadap segala hal yang berkaitan dengan makhlukNya yang sudah ada sejak jaman Azali. Segala sesuatu sudah diatur oleh Alloh swt, oleh karena itu kita seluruh manusia diwajibkan untuk percaya pada qada' dan qadar. Seperti contoh bait pupuh di atas yang menyatakan bahwa kematian itu sudah pasti dan percaya bahwa kematian itu adalah kembali kepada yang menciptakan-Nya.

Alloh menetapkan, siapa saja yang mencari agama selain dari agama Islam atau tidak mau taat pada ketentuan-ketentuan Alloh, maka dia akan menjaadi golongan orang yang rugi di akhirat nanti, karena dia sudah menyepelekan aqidah dan tauhid yang sesuai dengan fitrah manusia. Di bawah ini terdapat bait pupuh yang menggambarkan salah satu orang yang termasuk ke dalam golongan orang yang merugi, karena dia telah menyembah selain Alloh.
Horéng éta Ajam téa, jalma kafir//Majusi, nu nyembahna mangérana, ka seuneu ka panas deui, seungit ka kaom muslimin, mutuh hasud banget nyatru, tiap manggih jalma gepang, kana ngaruksak muslimin, popohoan nyiksa teu jeung kira-kira. 
Jin adalah satu makhluk yang termasuk dalam golongan roh, dia mempunyai akal dan diperintahkan juga untuk menjalankan syariat Islam seperti halnya manusia. Oleh karena itu, golongan jin sama dengan manusia, ada yang kafir dan ada juga yang Islam. Hal itu tergambar dalam bait pupuh di bawah ini:

\section{Kabéh jin di ieu gunung, ieu téh awal Jazair, kawilang Jazair Waq, sareng deui jisim kuring, nyekelan agama Islam, tohid ka maha suci.}

\section{2) Akhlak}

akhlak, dalam wawacan ini yang ditemukan adalah akhlak terpuji dan akhlak tercela. Akhlak yang terpuji disini adalah akhlak terpuji kepada Alloh, kepada RosulNya, dan kepada sesama manusia. Sedangkan akhlak tercela dalam wawacan ini hanya terdapat akhlak tercela kepada Alloh dan kepada sesama manusia.

Akhlak terpuji kepada Alloh bisa dilihat dalam bait puisi pupuh di bawah ini:

Carios // anu di nagari,

ibu Hasan gerwana,

kala mangsa dikantun téh,

tetep putri sareng ibu,

satu hari-satu hari,

barang dinten katiluna,

enéng putri nyaur,

subhanalloh maha mulya,

abdi aya di Bagdad geus tilu warsih,

teu pisan lebet ka hammam.

Subhanalloh artinya maha suci Alloh. Dalam bait pupuh di atas, terdapat kata pujian kepada Alloh. Memuji kepada Alloh merupakan salah satu akhlak terpuji yang wajib dilakukan oleh umat Islam. Sedangkan akhlak tercela kepada contohnya adalah putus harapan. Hal ini tergambar dalam salah satu bait pupuh di bawah ini:

Sundana nu sayaktosna, alit kasabaran kuring, tunangtos wuwuh nya aral, nu midamdam mingkin nyeri saparantos anjeun sepi, demi Alloh anu Agung, séép pisan kasabaran, papisah jeung buah ati, kumaha peta nyabaran pisah jeung anak.

Akhlak terpuji pada Rosul terdapat dalam bait pupuh di bawah ini:

\section{Mugi tetep ka anjeunna, ka Kanjeng Srimaha Nabi, rahmat Allah sareng salam, jeung ka sahabat anshori, sareng ka kabéh lihi, kadang warga kanjeng rosul, mugi tetep salawasna, rahmat salam téh ti Gusti, salajengna sok jiarah nu jiarah.}

Sholawat kepada Nabi berarti mengakui kerosulannya serta meminta kepada Alloh semoga Alloh melahirkan keutamaan dan kemuliaannya. Sedangkan salam artinya meminta kepada Alloh untuk keselamatan atau kebahagiaan untuk Rosul saw. Alloh memerintahkan kepada orangorang yang beriman untuk mengucapkan solawat dan salam untuk nabi Muhammad saw, para sohabat, dan keluarganya.

Saterasna gunem warta, raka rai sami calik dina katilu, ari geus kitu Sang Ayu, lajeng nyaur ka ninina, dirapihkeun sareng Nurul Huda ratu, supaya silih hampura, sampé sami saé galeuh.

Sikap saling memaafkan adalah satu sikap dan prilaku manusia yang sudah melakukan kesalahan. Walaupun kita sudah sangat sakit hati, namun kita tetap harus mempunyai sikap ini. Alloh tetap mengampuni umatNya walaupun sudah beberapa kali melakukan hal-hal yang dilarang oleh-Nya. 


\author{
Baréto sia ka aing, \\ nyapluk saha nu hianat, \\ kana sumpah uyah jeung és, \\ tangtu disiksa ku Alloh, \\ ayeuna sia buktina, \\ ditibakeun ku Yang Agung, \\ tinimbang nyawa pun paman.
}

Khianat merupakan sipat kaum munapik yang tidak disukai oleh Alloh, apalagi yang dikhianati adalah Alloh dan RosulNya. Sikap ini mudharatnya langsung kepada orang lain, misalnya saja sikap ini ada di tengah masyarakat, itu pertanda masyarakat tersebut akan hancur. Oleh karena itu, Alloh melarang orang yang beriman mempunyai sikap ini.

\section{3) Fiqih}

Fiqih yang terdapat dalam wawacan ini adalah perkara warisan, waktu dalam sholat fardhu, pernikahan, dan perkara seorang istri yang durhaka pada suaminya.

\section{Pinasti panggih nu pasti \\ nya wafat mulang ka Rohmat, \\ énggalna nu dicarios, \\ mayitna dipulasara, \\ barangna dibagi dua, \\ hiji-hiji putra tangtu, \\ nyandak sabagéan séwang.}

Dalam Al-qur'an sudah dijelaskan jenis harta yang dilarang untuk diambil dengan cara yang benar. Salah satu harta yang halal atau bisa diambil yaitu harta warisan. Dalam al-Qur'an sudah diatur cara membagi harta warisan dengan seadiladilnya, agar harta tersebut menjadi halal dan berkah.

Solat fardu, wajib dilaksanakan oleh setiap mukallaf (orang yang sudah baligh dan berakal) adalah lima kali dalam sehari semalam. Hal itu difirmankan oleh Alloh dalam QS. An-Nisa':103.

Waktu-waktu solat fardu adalah dzuhur, ashar, maghrib, isya, dan subuh. Dalam wawacan ini hanya terdapat waktu solat ashar, isya, dan subuh saja.

\section{Mugi-mugi Anu Maha Suci,}

\author{
maparinan kagampangan senang, \\ ima éngal-énggal maot, \\ wilujeng ucul, \\ tina kasusah syadaid, \\ lajengna solat janazah, \\ dina pinggir gunung, \\ nyolatkeun mayit anjeunna, \\ sanggeus kitu jleng ngajleng kana \\ jaladri, \\ nibakeun anjeun ka handap.
}

Solat jenazah hukumnya adalah fardhu kifayah. Jika dalam satu tempat tidak ada satu pun yang menyolatkan jenazah, maka seluruh masyarakat di tempat tersebut berdosa, namun jika ada sebagian yang menyolatkan, tetapi sebagiannya tidak, maka tidak berdosa orang-orang yang tidak menyolatkan tersebut.

Énggalna nu dipiwarta,
rempugan sadaya putri,
yén kudu aya saurang,
anu buat nampa wakil,
pikeun akad nikah putri,
jung hiji jadi panghulu,
Gan Putri geus ngaidinan,
lajeng dilapadan jadi,
akad nikah agan putri ka mas Hasan.

Pernikahan merupakan sunnah para nabi dan risalah para Rosul. Dalam pernikahan terdapat rukun-rukunnya, yaitu adanya calon pengantin laki-laki, calon pengantin perempuan, akad, wali, dan adanya dua orang saksi. Jika salah satu di antara rukun tersebut tidak terpenuhi, maka pernikahan tidak syah.
Bijil teu kalawan idin, nyulayapan amar akang, mugi ngahampura baé, da awéwé mah teu terang, ka pangaji pamegetna,
numawi dugi ka ngantun, ti salaki ngajauhan.

Salah satu hal yang bisa menjadikan seorang istri durhaka kepada suaminya adalah meninggalkan rumah tanpa sepengetahuan dan tanpa ijin dari suami. Jika suami melihat keadaan seperti itu, 
suami wajib untuk menasehati dengan sebaik-baiknya. Namun, jika sudah dinasehati sang istri tetap durhaka, maka suami harus pisah ranjang dengan sang istri. Jika masih tetap durhaka, maka diperbolehkan untuk memukul istri, tetapi tidak untuk merusak badannya.

\section{Bahan Ajar Membaca}

Wawacan ini bisa dijadikan bahan pembelajaran membaca di tingkat SMA berdasarkan SKKD pengajaran basa Sunda di SMA. Dalam membaca wawacan, siswa dituntut untuk paham bukan hanya wawacan yang dibacanya saja, melainkan dengan struktur dan nilai agamanya.

\section{SIMPULAN}

Wawacan Hikayat Hasan Shoig Bashri merupakan wawacan yang dikarang oleh Haji Muhyidin. Téks wawacan ini, dibagi ke dalam 2 jilid yang masing-masing jilid terdapat 64 halaman.

Tema dalam waawacan ini adalah kehidupan sosial seorang pemuda yang sangat taat pada agama yang dianutnya. Alur yang digunakan adalah alur maju.

Dalam wawacan ini tercatat 33 orang pelaku, yang tokoh utamanya bernama Hasan Shoig Bashri.

Secara umum latar yang digunakan adalah latar yang erat hubungannya dengan agama Islam. Sudut pandang dalam wawacan ini menggunakan sudut pandang orang pertama dan orang ketiga.

Gaya bahasa yang digunakan dalam wawacan ini adalah bahasa yang teratur sesuai patokan dalam aturan puisi pupuh, kata-kata yang berkaitan dengan keagamaan (agama Islam), yaitu syair-syair Arab, pribahasa Sunda, gaya bahasa personifikasi, perbandingan, hiperbola, dan purwakanti.

Nilai agama yang dianalisis dalam wawacan ini meliputi aqidah, akhlak, dan fiqih.

Aqidah yang terdapat dalam wawacan ini di antaranya adalah iman kepada Alloh, iman kepada qada' dan qadar (takdir), orang kafir akan rugi, dan adanya jin-jin yang diciptakan sama dengan manusia. Akhlak yang ditemukan adalah akhlak terpuji kepada Alloh, kepada RosulNya, dan kepada sesama manusia. Sedangkan akhlak tercela dalam wawacan ini hanya terdapat akhlak tercela kepada Alloh dan kepada sesama manusia.

Fiqih yang terdapat dalam wawacan ini adalah perkara warisan, waktu dalam sholat fardhu, pernikahan, dan perkara seorang istri yang durhaka pada suaminya.

Wawacan ini bisa dijadikan bahan pembelajaran membaca di tingkat SMA berdasarkan SKKD pengajaran basa sunda di SMA.

\section{PUSTAKA RUJUKAN}

Anshari, H. E.S. (2004). Wawasan Islam (Pokok-Pokok Tentang Paradigma dan Sistem Islam). Jakarta: Gema Insani.

Ekadjati, E. S. (1988). Tersedia di: Http://file.upi.edu/Direktori/FPBS/JUR .PEND._BAHASA_DAERAH/19641 1101989032-RUHALIAH/materi kuliah_teks/analisis_struktur_\%26_nila i_budaya.pdf (22 Februari 2012)

Iskandarwassid. (2003). Kamus Istilah Sastra. Bandung: CV. Geger Sunten.

Koentjaraningrat. (1985). Kebudayaan, Mentalitas, dan Pembangunan. Jakarta: PT. Gramedia.

Koswara, Dedi. (2009). (Diktat) Racikan Sastra. Bandung: Jurusan Pendidikan Bahasa Daerah FPBS UPI.

Ruhaliah. (2007). (Diktat) Sejarah Sastra Sunda. Bandung: Jurusan Pendidikan Bahasa Daerah FPBS UPI.

Ruhaliah. (2011). Wawacan: Sebuah Genre Sastra Sunda. Bandung: Jurusan Pendidikan Bahasa Daerah Fakultas Pendidikan Bahasa dan Seni Universitas Pendidikan Indonesia.

Stanton, R. (2012). Teori Fiksi Robert Stanton. Yogyakarta: Pustaka Pelajar.

Tamsyah, B.R., Purmasih, dan Purmawati, T. (1999). Kamus Istilah Tata Basa jeung Sastra Sunda. Bandung: CV. Pustaka Setia. 
Rindi Vaivti Melandi, dkk.: Nilai Agama Dalam Wawacan Hikayat... | 161

\section{Tarigan, H.G. (1984). UCAPAN TERIMA KASIH}

Http://annadewigalery.blogspot.com/2 Terima kasih penulis sampaikan 011/11/nilai-nilai-yang-terkandungdalam-novel.html (04 Februari 2013). kepada semua pihak yang telah membantu penelitian ini, terutama kepada Penyunting Jurnal Lokabasa atas dimuatnya tulisan ini. 